\title{
A Hypertextual Novel That Dramatizes the Process of Its Creation and Proposes Techniques to Increase Creativity
}

\author{
Raffaele Calabretta \\ Institute of Cognitive Sciences \\ Italian National Research Council \\ Rome, Italy \\ raffaele.calabretta@istc.cnr.it
}

"Why can't I decide to be happy?" This is the question that encapsulates the meaning behind Gabriele's story, the main character of the novel Il film delle emozioni (The Movie of Emotions; Calabretta 2007a, in Italian).

Gabriele is a victim of his negative emotions, and is completely in the power of his self-blame and self-devaluative thinking, which he learns to change only at the end of the novel, thanks to creativity and to the artistic expression of his own traumatic experiences (see Sparrow and Wegner 2006).

The novel tells of Gabriele's several attempts at writing, first, the script of an autobiographical "educational" movie on emotion regulation; and then at transforming it into a novel. In reality, it reveals itself as a book popularizing the most recent scientific knowledge on psychology of emotions; as a dramatization of a scientist's life_-of his interior, interpersonal, and social conflicts (as well as political ones); and as a dramatization of the creative process of writing.

As we will see in this article, The Movie of Emotions is a very particular novel that has much to do with creativity viewed in three different aspects-creativity in the novel's structure, creativity in the process of the novel's creation, and proposed techniques to increase creativity.

\section{The Novel's Structure Is Experimental, Complex, and Hypertextual}

The Movie of Emotions is an experimental book that can be defined as a novel. The validity of this definition is confirmed by several e-mails from readers of the book in which it is possible to see their process of identification with the main character of the novel, Gabriele. However, it is a very particular novel, a type of borderline literature that mixes registers and genres and does not fall within one classification: novel, autobiography, essay on emotions, movie screenplay, diary, and also a manual on how to live (as defined by Italian literary critic Filippo La Porta in the newspaper Il Messaggero).

Recently in the journal Nature, Rohn (2006) defined a new literary genre, "laboratory literature" (lab-lit). These are novels "containing realistic depictions of scientists plying their trade," and, therefore, are different from fanciful science fiction. Perhaps The Movie of Emotions belongs to this genre. Or better, paraphrasing Dyerassi's definition, it is a "structural science-in-fiction novel"; i.e., it belongs to a new literary genre or sub-genre in which a novel's structure conveys scientific theories (e.g., complex systems theory principles: emergence, adaptive behavior, (un)predictability; Calabretta, in preparation) and research results (research work on the evolution of brain modularity; Calabretta et al. 2000).

The book tells the story of Gabriele, a researcher for the Italian National Research Council (CNR). His biography, daily work, conflicts, and the evolution of his personality are laid out. In other words, at the beginning of the book, the reader discovers the origins and existential problems of the main character; later in the novel, the reader is hit with a succession of coups de thêatre and is convinced of the definitive change in Gabriele's personality. It is a complex structure in which there is a prologue, an epilogue, a beginning, and an end to the story; the middle, a predominant section of the book, is called "Files." These files look like computer files with a file name and a file extension (e.g., "Diary.doc"), and in the book are pasted together without any apparent order. Thus, most of the novel's structure is created by dropping the typical book constraint of having chapter divisions. As a result, the structure is composite: It is not divided in chapters, but is a digital miscellany made up of a variety of materials set in different typographical styles (that construct the aesthetic architecture of the novel): diary pages, sketches, email exchanges, summaries of films, bits of the news, parts of film scripts, excerpts from scientific papers, jottings. There is even a file denominated as "TitoloLibro.doc" (BookTitle.doc), in which Gabriele lists all the alternative possible titles for his book. The novel's structure is also a metaphor for human brain structure: the "files" section reminds us of the emotional 
memory stored in the amygdala and hippocampus memory systems (see Dolcos et al. 2005); the prologue, the epilogue, and the beginning and end of the story remind us of the frontal lobes of the cerebral cortex, which are involved in the control of movement, in the regulation of emotions (see Davidson 2002), in the suppression of emotional memories (see Depue et al. 2007), and in working memory, planning, organizing, and problem-solving.

According to La Porta (2004), the more interesting literary experimentation has not to do with language or transgression practices but with a free mixture of genres that comes from the urgency of finding reality again or renaming it. This definition applies to The Movie of Emotions. The novel's structure mixes the classical dramaturgical division of three acts with the chaotic features of our times. As has already been said, the book is mainly a fragmented and modular combination of files: This original structure represents a metaphor of the nature of modern man's work activity plunged into technologies that prevent him from concentrating and working on the same task for more than four minutes before being interrupted by e-mails or cellular phone text messages. Moreover, reading the whirling succession of files, of which the novel is composed, is reminiscent of the working activity of modern man as he jumps from one computer file to another. Readers have very much appreciated this feature because it allowed them to undertake a fragmented reading of the book. Some readers did a very original reading: first they read all the diary pieces; then all the movie script pieces; then all the scientific paper sections; and so on. There is also another hypertextual aspect to the book. It tells the story of Gabriele, and apparently there are no other main characters, only secondary characters, which are not defined in their personalities. In reality, the story of Gabriele is enriched by the characters of the movies cited in the book, which have been selected with this specific function, with a multiplicative effect. For example, in the novel the personality of Michela-Gabriele's companion—is only sketched in, but it acquires character dimension if the reader recalls the personality of Grazia, the main character of the successful Italian movie Respiro (Crialese 2002).

The reader of the book thinks that the structure of the novel is linear from a temporal point of view. At the end of the book, he understands that the entire story unfolds during an hour-long run in Aniene Park in Rome on the last day of the year, during the course of which Gabriele has a flashback of the whole year that has gone by (i.e., 2003). A similar process happens with emotions in our brain. For example, when you have to make a complex decision, you think that you are considering future rational consequences of possible alternatives; in reality, the body's nonconscious somatic markers of past emotional experiences will direct attention and guide advantageous behavior in the decision process (Bechara et al. 1997). As with the book's structure, this is a sort of emo- tional flashback. At the end of the novel, as a coup de théâtre, Gabriele discovers that many decisions of his life have been unconsciously guided by emotions.

According to the editor of the novel, using the definition of literary critic Moretti (1996), the book is an example of "world-text" (tendency to digressions, weak conclusions, stream of consciousness, aspiration to totality, encyclopedic drive toward totality, etc.); while taking the Enzensberger definition, the book is an example of an "Alka-Seltzer" novel that, like the tablet in water, crumbles in thousands of narrative bubbles. Gabriele's identity is a puzzle that the reader creatively reconstructs by means of the accumulation of details scattered throughout the book in the narrative forms (in the diary, in the e-mails, in the scientific papers, in the movie script; as well as in the appendix and the lists (with notes) of the books read and movies seen). The identity of the main character also emerges from the languages of the different narrative forms present in the novel: from the first-person direct and colloquial language of the daily diary to the third-person formal and aseptic language of the scientific paper about the emotions at work, along with the strong evocative language of the movie's story and screenplay. In the movie's story, in particular, Gabriele's actions, dramatic requirements, standpoint, manner, and changes are described.

\section{The Novel Dramatizes the Process of Its Creation}

Some Italian literary critics have defined The Movie of Emotions as "new, original, courageous, audacious, that forces all the genres" (Galateria D., personal communication, January 2007). To better understand from where its originality is derived, it is useful to take a quick look at the different phases of the novel's creative process.

I decided to write this book because the same thing happened to me that happens to Gabriele in the novel. As a researcher at CNR and a professor of educational technologies at the University of L'Aquila, I received a proposal to teach a course in work and organizational psychology at the University of Rome. In order to prepare the course lessons, I started to study the literature on the topic, and being an emotive person, I became very interested in the relationship between emotions and work environment and organization. Because of research fund cuts, the said course at the University of Rome was never activated, but I decided to popularize the large amount of material that I had studied.

The project began in the form of a scientific paper on the psychology and neuroscience of emotions; then, it was transformed into a screenplay for an autobiographical movie on emotions. Nevertheless, in 2002, even famous Italian movie directors had difficulty finding money for making their movies: eventually, the screenplay became a novel. 
The originality of the novel's structure, therefore, depends very much on the generative process (see Boden 1996: 78). This generative process is explicitly dramatized in the novel, in part as a direct dialogue between the writer and the reader. In fact, according to Italian movie director Nello Correale (personal communication, 12 October 2006), this novel belongs to that genre of books in which the writer does not present his literary conjuring trick to readers, but rather the conjuring trick emerges from the dialogue between the writer and the reader.

\section{The Novel Proposes Techniques to Increase Creativity Based on Recent Studies on Brain Functioning}

Gabriele is unhappy and, in an attempt to modify and improve the quality of his existence, spends his time meditating, remembering, reading, writing his diary and scientific papers, seeing and studying movies, and going for a jog. Gabriele goes for a run in the park close to his home in order to feel good, and, in certain aspects, has a paradoxical relationship with jogging. He is a scientist who works in the field of cognitive sciences and studies how the mind functions and evolved biologically. At the same time, he is a man affected by deep emotional problems: He is passing through a very difficult period, professionally and personally, and experiences fear, sadness, and anger intensely. With respect to non-scientists, Gabriele has an additional tool at his disposal that could enable him to feel better: the study of scientific literature on the psychology and neuroscience of emotions, by means of which he gradually discovers some very counterintuitive processes of body and mind. For example, he learns that one of the best ways to increase your energy when you feel tired is physical exercise. The novel dramatizes recent studies by American scientists who have classified the success of different activities as good strategies in relation to a person's psychophysical state (Thayer et al. 1994).

When he goes for a run, Gabriele is looking not only for physical but also psychological well-being. He looks for solutions to personal and professional problems: during the run, he so quickly inspects all his recent experiences and disturbing thoughts that there is no room for repetitive and inconclusive brooding over problems; environmental stimuli continually send new signals to the brain, which produces new points of view and associations of ideas.

Synthetically, running has such a beneficial creative effect that it creates a positive dependence in Gabriele, just as in all runners ("positive addiction" as opposed to drugs, which produce negative dependence; see Glasser 1976; Holden 2001). Gabriele goes out to run when he has a problem and has to find a solution. In the appendix of the novel, the reader finds a description of the so-called "creative emotional running" strategy, which puts together advantages of physical activity with those of meditation. It is a 12-step technique, which is a sort of guide for different creative problems (school homework, work deadlines, etc.) and helps to find solutions, thanks to body movements during running. The efficacy of these techniques seems to be confirmed by the more recent theories on brain mechanisms of functioning of implicit thought and intuition, which correlate body movements and creativity through the cerebellum's activity (Vandervert et al. 2007; Ito 2008): Creativity springs from collaboration between working memory in the brain's frontal lobes and the cerebellum that adaptively models all bodily movement and processes of working memory.

Another technique implemented in the novel's structure consists of the fact that during the working day jumping from one activity to another-not focusing on only one activity-is more efficient in order to avoid the ironic processes of mental control that make us obtain effects diametrically opposed to the original intent (see Wegner 1994). Gabriele tries to heal his emotional problems by means of creative practices: first, writing an autobiographical movie, and then transforming it into a novel.

The novel implicitly describes an attentional phenomenon (latent inhibition) that links irrelevant information, mental illness, and creativity. Latent inhibition refers to "the varying capacity of the brain to screen from current attentional focus stimuli previously experienced as irrelevant" (Carson et al. 2003: 499); decreased latent inhibition (i.e., reduced capacity to ignore irrelevant stimuli) has been not only associated with a tendency toward psychosis but also with original thinking, particularly in the presence of high intelligence quotient (IQ). During his working day, Gabriele is distracted by all irrelevant information that comes from a variety of sources, such as e-mails, newspapers, websites, cellular phone, text messages, etc. This behavior negatively affects his psychological well-being and seems to reduce his productivity, but eventually stimulates and improves his ability to combine pieces of new information in a creative way. Gabriele saves everything that he writes, reads, lives, and thinks in the computer files (written in a variety of fonts and typographical styles) that, as has already been explained, become the creative composite structure of this novel. The result is a book structure that is branched, hyper-detailed, and fractalic, and has been defined by readers as "an esthetically very beautiful object" (Grignani P., personal communication, July 2006). In this respect, it is interesting to note that "Barron also suggested that creative products are generally characterized by elegance" or an "esthetic fit" (Barron 1969: 20, cited in Carson et al. 2005).

\section{Conclusion}

As I have already noted, the originality of the novel, The Movie of Emotions, depends on many factors related to creativity. It is important to stress that being such an experimental novel, 
it required a long and difficult phase of research to get a publisher. According to one Italian publisher, the central idea of the novel (and its related structure) was an optimal one, but the fusion between the essay and the narrative parts was not successful. According to another Italian publisher, which specializes in publishing essays, the book was not orthodox from a scientific point of view. After the difficulty of finding the right publisher for this very particular novel, the book was very well received by critics and readers (e.g., "It's very difficult to insert scientific content in novels. You were able to," Cormac McCarthy, winner of 2007 Pulitzer Prize for Fiction; personal communication, 6 January 2007), and was featured in major magazines, newspapers, and television shows. In Italy the novel was reviewed favorably by some of the most important literary critics, famous writers, and scientists from psychological and psychoanalytical websites and journals. It has been presented at the Italian Science Academy, Accademia dei Lin$c e i$, and in various conferences, festivals, and universities. The book has also been used as a text for psychology and creative writing at several Italian universities. It also provoked interest in communication sciences faculties and in screenwriting programs. Somebody proposed it as a self-help text for young couples and people with emotional problems. Although the novel has been published only in Italy, it has aroused interest in the United States: The experimental structure of the novel was presented in Boston at the International Conference of Complex Systems (Calabretta 2007b), followed by a favorable review ("Great idea in the spirit of experimental literature") by Jessica Lipnack (personal communication, November 2007), who is a pioneer in the science of networked organizations (see http://endlessknots.typepad.com).

Elster in the book Ulysses Unbound: Studies in Rationality, Precommitment, and Constraints (2000), argues that constraints may be very advantageous from a creative point of view. The Movie of Emotions has been built according to the "incidental constraints" described above, and this could be one of the reasons for its originality.

Even though tens of thousand of people have downloaded the book (http://www.gaffi.it/document/upload/ ingegni/calabretta.pdf), the first edition was sold out and very recently the second has been published. (And the creative process of the book is going to continue: a new screenplay, adapted from the novel, but also very different from it, is already underway.)

\section{References}

Barron F (1969) Creative Person and Creative Process. New York: Holt, Rinehart.
Bechara A, Damasio H, Tranel D, Damasio AR (1997) Deciding advantageously before knowing the advantageous strategy. Science 275: 1293 1294.

Boden, MA (1996) Dimensions of Creativity. Cambridge, MA: MIT Press.

Calabretta R (2007a) Il film delle emozioni (The Movie of Emotions), 2nd ed. Rome: Gaffi.

Calabretta R (2007b) The Movie of Emotions: A novel's experimental modular structure that conveys scientific theories and research findings. In: Proceedings of the International Conference on Complex Systems (Bar-Yam Y, ed), 32. Cambridge, MA: New England Complex Systems Institute.

Calabretta R (in preparation) A novel's structure as a complex system.

Calabretta R, Nolfi S, Parisi D, Wagner GP (2000) Duplication of modules facilitates the evolution of functional specialization. Artificial Life 6: 6984.

Carson SH, Peterson JB, Higgins DM (2003) Decreased latent inhibition is associated with increased creative achievement in high-functioning individuals. Journal of Personality and Social Psychology 85(3): 499506.

Carson S, Peterson JB, Higgins DM (2005) Reliability, validity and factor structure of the creative achievement questionnaire. Creativity Research Journal 17: 37-50.

Crialese E (2002) Respiro (Italian movie). Rome: Fandango (producer).

Davidson R (2002) Anxiety and affective style: Role of prefrontal cortex and amygdala. Biological Psychiatry 51: 68-80.

Depue BE, Curran T, Banich MT (2007) Prefrontal regions orchestrate suppression of emotional memories via a two-phase process. Science 317: 215-219.

Dolcos F, LaBar KS, Cabeza R (2005) Remembering one year later: Role of the amygdala and medial temporal lobe memory system in retrieving emotional memories. Proceedings of the National Academy of Sciences of the USA 102: 2626-2631.

Elster J (2000) Ulysses Unbound: Studies in Rationality, Precommitment, and Constraints. Cambridge, UK: Cambridge University Press.

Enzensberger HM (1991) La letteratura come istituzione ovvero l'effetto AlkaSeltzer. In: Mediocritàe follia (Enzensberger HM, ed.). Considerazionis parse, 35-41 Milano-Garzanti.

Glasser W (1976) Positive Addiction. New York: Harper \& Row.

Holden C (2001) "Behavioral" addictions: Do they exist? Science 294: 980 982.

Ito $\mathrm{M}$ (2008) Control of mental activities by internal models in the cerebellum. Nature Reviews Neuroscience 9: 304-313.

La Porta F (2004, April) Cos'è oggi sperimentale? Rivista dei libri 14(4): $10-12$.

Moretti F (1996) Modern Epic: The World-System from Goethe to Garcia Marquez. London: Verso.

Rohn J (2006) Experimental fiction. Nature 439: 269.

Sparrow B, Wegner DM (2006) Unpriming: The deactivation of thoughts through expression. Journal of Personality and Social Psychology 91: $1009-1019$.

Thayer RE, Newman JR, McClain TM (1994) Self-regulation of mood: Strategies for changing a bad mood, raising energy, and reducing tension. Journal of Personality and Social Psychology 67: 910-925.

Vandervert L, Schimpf P, Liu H (2007) How working memory and the cerebellum collaborate to produce creativity and innovation (special issue). Creativity Research Journal 19(1): 1-19.

Wegner DM (1994) Ironic processes of mental control. Psychological Review 101: 34-52. 